
\title{
25 Research Suare \\ Serum Fatty Acid Binding Protein 5 (FABP5) as a Potential Biomarker of Inflammation in Psoriasis.
}

\section{Dorota Kozłowska}

Uniwersytet Medyczny w Bialymstoku

Hanna Myśliwiec ( $\nabla$ hanna.mysliwiec@gmail.com )

Uniwersytet Medyczny w Bialymstoku

\section{Ewa Harasim-Symbor}

Uniwersytet Medyczny w Bialymstoku

\section{Anna Milewska}

Uniwersytet Medyczny w Bialymstoku

\section{Adrian Chabowski}

Uniwersytet Medyczny w Bialymstoku

Iwona Flisiak

Uniwersytet Medyczny w Bialymstoku

\section{Research}

Keywords: psoriasis, E-FABP, FABP5, obesity, NB-UVB

Posted Date: July 16th, 2020

DOI: https://doi.org/10.21203/rs.3.rs-41783/v1

License: (c) (1) This work is licensed under a Creative Commons Attribution 4.0 International License. Read Full License

Version of Record: A version of this preprint was published at Molecular Biology Reports on May 1st, 2021. See the published version at https://doi.org/10.1007/s11033-021-06461-3. 


\section{Abstract}

Background: Psoriasis is an immune-mediated chronic inflammatory disease with cardiometabolic comorbidities. Fatty acid binding protein 5 (FABP5) is elevated in human psoriatic keratinocytes and could be potentially involved in systemic metabolic disturbances. The aim of the study was to evaluate serum FABP5 in psoriatic patients, to assess the relationship between FABP5 and the duration, severity of the disease, inflammatory and metabolic markers and influence of treatment with narrowband UVB (NBUVB).

Methods: A total of 74 patients with active plaque-type psoriasis and 30 healthy controls were enrolled in the study. Thirty patients were treated with NB-UVB. Patients were divided into subgroups based on their BMI (Body Mass Index) and disease severity measured by PASI (Psoriasis Area and Severity Index). The serum concentrations of FABP5 were measured using commercially available Human FABP5 ELISA kit. Total serum fatty acids content and composition was measured by gas-liquid chromatography and flame ionization detector after direct in situ transesterification

Results: Serum FABP5 levels in psoriatic patients (both obese and non-obese) were higher versus control group $(p<0.001)$. FABP5 in patients with PASI $>20$ was higher compared to the mild group $(P A S I<10)$ $(p<0.001)$ and serum FABP5 correlated positively with PASI score $(r=0.41, p<0.001)$. We found positive correlation between FABP5 and basic inflammation indices: C-reactive protein, white blood cell count and the platelet count. Decrease of PASI after NB-UVB treatment $(p<0.001)$ was observed and accompanied by decrease of the serum FABP5 $(p=0.007)$.

Conclusion: FABP5 is a potential marker of psoriasis, its severity and clinical outcome after therapy with NB-UVB. FABP5 may reflect metabolic disturbances and might be the potential missing link between psoriasis and metabolic disturbances.

\section{Introduction}

Psoriasis is an immune-mediated, chronic inflammatory skin disease of complex patomechanism. Several studies have shown that psoriasis is associated with systemic disorders specially metabolic syndrome (MS), which is defined as a constellation of insulin resistance, obesity, hyperlipidemia and hypertension [1, 2] Psoriatic patients are also predisposed to other comorbidities like: inflammatory bowel diseases, cardiovascular diseases and non-alcoholic fatty liver disease (NAFLD) [3-5]. It has been established that the release of inflammatory molecules and cytokines play an important role in metabolic disturbances and atherosclerosis in the course of psoriasis [6]. On the other hand, there are some evidence that pre-existing obesity or MS increase the risk of development of psoriasis [7]. The possible explanation of this bilateral interinfluence is the chronic, systemic metabolic inflammatory state, termed metaflammation [8]. Despite of advancement in medical science and new methods of psoriasis treatment, mortality rate in psoriatic patients is still $20 \%$ higher than in the general population [9]. 
Although abnormalities in lipid metabolism play an important role in the pathogenesis of psoriasis and its comorbidities, the exact underlying mechanism is complex and still unclear.

In recent years, a number of proteins facilitating fatty acid transport, including fatty acid binding protein (FABP) have been identified. These proteins, do not only buffer lipids, but also are crucial mediators of metabolic and other biological activities [10]. In previous studies increase of serum FABP2, FABP4 in the psoriatic patients have been found [11, 12]. Fatty acid binding protein 5 (FABP5, E-FABP) is a lipid carrier, originally discovered in human epidermis. FABP5 is predominantly expressed on keratinocytes, but also abundantly in adipose tissue (adipocytes and macrophages), in thymus and tongue epithelia $[13,14]$. Psoriatic post mitotic keratinocytes overexpress FABP5, as compared to the keratinocytes, in normal epidermis. FABP5 induces differentiation in normal human keratinocytes and modulates the differentiation process in psoriatic keratinocytes in vitro [14]. Although the role of FABP5 in the keratinocytes in psoriatic epidermis has been already elucidated, the role of circulating FABP5 has not been studied extensively in this population. From other studies we know that FABP5 may represent mediators of and biomarkers for metabolic and cardiovascular disease in type 2 diabetes mellitus, thus it could play an important role and contribute to the development of cardiometabolic comorbidities in psoriasis $[15,16]$.

The aim of the present study was to evaluate serum concentration of FABP5 in psoriatic patients and to assess the relationship between FABP5 and the duration and the severity of the disease as well as the inflammatory and metabolic markers. Additionally, we have also investigated the influence of NB-UVB treatment of psoriasis on FABP5 serum concentration.

\section{Methods}

\section{Subjects and examination}

The study was conducted on 74 patients ( 25 women and 49 men) with exacerbated plaque psoriasis aged 19 to 79 years (mean 50,7 +/- 14.5 years) with active plaque-type psoriasis and 30 sex- and agematched healthy controls. None of the patients or controls were under any dietary restriction. All patients were white people and had skin phototype II and III. They did not use phototherapy or any other systemic therapy of psoriasis during the previous 3 months. Patients suffering type II diabetes, liver disease, using lipid-lowering drugs, and systemic therapy for psoriasis were excluded from the study. The duration of psoriasis varied from 1 to 58 months (mean 18.7 months). The severity of psoriasis was assessed using PASI (Psoriasis Area and Severity Index) score [35]. All subjects gave their informed consent for inclusion before they participated in the study. The study was conducted in accordance with the Declaration of Helsinki, and the protocol was approved by the Bioethical Committee of the Medical University of Bialystok, Poland (No: R-I-002/457/2016).

\section{UVB treatment}


The group of 30 patients underwent NB-UVB treatment. Blood was collected twice: before and after phototherapy. The treatment schedule comprised irradiations three times a week, starting from the dose $0.020 \mathrm{~J} / \mathrm{cm} 2$ for the II phototype and $0.024 \mathrm{~J} / \mathrm{cm} 2$ for the III phototype. The dose was increased by approximately $10 \%-20 \%$ per week, depending on skin type, tolerance and clinical response to the therapy. In case of signs of burning, the dose was diminished or the treatment was stopped for two-three days. TL01 lamps (Cosmedico Medizintechnik $\mathrm{GmbH}$, Germany) were used as a source of irradiation (wavelength of 311-313 nm). Some patients completed 20 lamp treatment, some finished irradiations earlier for different family and social reasons. The patients underwent $14.9+/-4.5(\min 6, \max 20)$ irradiations and their cumulative dose was $0.84+/-0.43 \mathrm{~J} / \mathrm{cm}^{2}(\min 0.2, \max 2.28)$. During the whole period of irradiations the patients were asked to apply only topical emollients on the skin. PASI, the number of irradiations and the total dose of irradiations at the end of the treatment were calculated.

\section{Blood collection and analyses}

Blood was taken after overnight fast before starting the treatment. In the group of patients treated with NB-UVB the blood was collected twice: before and after phototherapy, after overnight fast. After centrifugation the samples have been stored at $-80^{\circ} \mathrm{C}$ until analysis.

The serum concentrations of FABP5 were measured using commercially available Human FABP5 ELISA kit (BioVendor, Czech Republic). All assay procedures were conducted following the manufacturer's instruction. Four fold dilution of each sample was required before analysis. The limit of detection for FABP5 was $0.066 \mathrm{ng} / \mathrm{ml}$, and the standard curve range was between 1-40 ng/ml. Intra- and inter-assay coefficients of variations were equal to $5.8 \%$ and $6.1 \%$, respectively. At the end of the procedure the intensity of colored product was measured in a hybrid multi-mode microplate reader (Synergy $\mathrm{H} 1^{\mathrm{TM}}$, Biotek Instruments, USA) at $450 \mathrm{~nm}$ wavelength and the absorbance of the samples was plotted on standard curve. The biochemical analysis including C-reactive protein (CRP), serum fasting blood glucose (FBG), total cholesterol, HDL, LDL, triglycerides (TG), aspartate transaminase (AST), alanine transaminase (ALT), bilirubin were performed in the Central Laboratory of our University Hospital Center.

Total serum fatty acids content and composition was measured according to a method by Glaser et al. [36]. Briefly, $100 \mu \mathrm{l}$ of serum was incubated in $85^{\circ} \mathrm{C}$ for 45 minutes in $1.5 \mathrm{ml}$ of $3 \mathrm{~N}$ methanolic $\mathrm{HCl}$ containing $2 \mathrm{~g} / \mathrm{l} \mathrm{BHT}$ (2,6-di-tert-butyl-p-cresol, antioxidant). Prior to incubation, $100 \mu \mathrm{l}$ of internal standard mixture (heptadecanoic acid, cholesteryl-heptadecanoate, triheptadecanoate, diheptadecanoate and diheptadecanoyl-phosphatidylcholine; $0.2 / 2 / 1.5 / 0.2 / 2$ per weight, $10 \mu \mathrm{g}$ of $\mathrm{C} 17: 0$ total, in chloroform/methanol 2:1) was added to account for methylation and extraction losses. After cooling to room temperature, fatty acids methyl esters were extracted with $0.5 \mathrm{ml}$ hexane, $30 \mathrm{~s}$ of vortexing and centrifugation (3000 $\mathrm{g}$ for $5 \mathrm{~min}$ ). A volume of upper organic phase was transferred glass vials and $1 \mu \mathrm{l}$ of sample was analyzed by gas-liquid chromatography using a Hewlett-Packard 5890 Series II gas chromatograph, a Agilent J\&W CP-Sil 88 capillary column $(50 \mathrm{~m} \times 0.25 \mathrm{~mm}$ I.D.) and flame-ionization detector. The oven temperature was programmed from $130^{\circ} \mathrm{C}$ to $220^{\circ} \mathrm{C}$ at $5^{\circ} \mathrm{C} / \mathrm{min}$ and held at $220^{\circ} \mathrm{C}$ 
for 32 minutes. Argon was used as carrier gas. The following fatty acid species were identified and quantified according to respective retention times of synthetic standards: myristic (14:0), palmitic (16:0), palmitoleic (16:1n-7), stearic (18:0), oleic (18:1n-9), linoleic (18:2n-6), a-linolenic (18:3n-3), arachidic (20:0), arachidonic (20:4n-6), eicosapentaenoic (20:5n-3), behenic (22:0), docosahexaenoic (22:6n-3), lignoceric (24:0) and nervonic (24:1n-9) acids. The FA were additionally grouped according to their biologic properties. The percentage of SFA (myristic acid, palmitic acid, stearic acid, arachidic acid, behenic acid, lignoceric acid) were measured and calculated. Unsaturated fatty acids (UFA) were divided into monounsaturated fatty acids (MUFA) (palmitoleic acid, oleic acid, nervonic acid), and polyunsaturated fatty acids (PUFA) (n-3 PUFA: a-linolenic acid, eicosapentaenoic acid (EPA), docosahexaenoic acid (DHA) and n-6 PUFAs: linoleic acid, arachidonic acid.

\section{Statistical analyses}

The data analyses were carried out using Statistica 12.0 software. Descriptive statistics were used to show sociodemographic and biochemistry characteristics of the study groups. We examined the distribution of each continuous variable using Shapiro-Wilk test. We have not found the normal distribution of the analyzed variables. Data were presented as median and quartiles (first and third quartile) and percentage when appropriate. The statistical analysis were performed using Mann-Whitney tests and Kruskal-Wallis tests. The correlations between the serum FABP5 and metabolic and clinical variables were determined by Spearman's rank correlation analysis. Results on the level $p<0.05$ were regarded as significant.

\section{Results}

A total of 74 patients ( 25 women and 49 men) with exacerbated plaque psoriasis patients, aged 19 to 79 years (mean 50,7 +/- 14.5 years), and 30 age- and sex-matched healthy controls were enrolled in the study. The selected clinical and demographic data of the patients are summarized in Table 1. The median severity of the disease measured by PASI was 9.05 (from 1,4 to 38,3). Disease duration ranged from 1 to 58 months (mean 18,7 months). In the study group 43 patients (58.1\%) had mild disease (PASI < 10), 21 (28.4\%) had moderate disease (PASI 10-20) and 10 (13.5\%) were diagnosed with severe disease (PASI > 20). 
Table 1

Clinical and laboratory characteristics of the psoriatic patients. Data shown as median and quartiles $\left(Q_{1}\right.$ first quartile; $\mathrm{Q}_{3}$ third quartile) and percentage. (BMI- body mass index, PASI - psoriasis area and severity index, CRP

- c-reactive protein, WBC - white blood cells, PLT platelet count, FBG - fasting blood glucose, TG triglycerides)

\begin{tabular}{|ll|}
\hline & $\begin{array}{l}\text { Psoriasis }(\mathbf{n}=74) \\
\text { Median }(\text { Q1, Q3) }\end{array}$ \\
\hline Age $($ years $)$ & $54.0(41.0 ; 59.0)$ \\
\hline BMI $\left(\mathrm{kg} / \mathrm{m}^{2}\right)$ & $27.17(23.89 ; 33.09)$ \\
\hline Men : Women & $49(66.2 \%): 25(33.8 \%)$ \\
\hline Psoriasis duration (months) & $17.0(6.0 ; 30.0)$ \\
PASI & $9.05(5.9 ; 13.8)$ \\
CRP $[\mathrm{mg} / \mathrm{dl}]$ & $2.7(1.2 ; 5.9)$ \\
WBC $\left[\times 10^{3} / \mathrm{ml}\right]$ & $7.09(6.08 ; 8.27)$ \\
PLT $\left[\times 10^{3} / \mathrm{ml}\right]$ & $215(192.0 ; 257.0)$ \\
FBG $[\mathrm{mg} / \mathrm{dl}]$ & $87(77 ; 98)$ \\
Cholesterol $[\mathrm{mg} / \mathrm{dl}]$ & $177(156 ; 198)$ \\
TG $[\mathrm{mg} / \mathrm{dl}]$ & $108(79 ; 151)$ \\
\hline
\end{tabular}

The median serum FABP5 concentration $(16.28 \mathrm{ng} / \mathrm{ml})$ in the study group was significantly higher than in the healthy controls $(7.82 \mathrm{ng} / \mathrm{ml})(p<0.001)($ Fig. 1).

To avoid the influence of obesity on the study results, we divided the examined group to non-obese patients $\left(n=50, B M l<30 \mathrm{~kg} / \mathrm{m}^{2}\right)$ and obese patients $\left(n=24, B M I \geq 30 \mathrm{~kg} / \mathrm{m}^{2}\right)$. Both obese and non-obese psoriatic patients had higher FABP5 than the healthy control group $(p<0.001$ and $p<0.001$ respectively) (Fig. 2).

Based on psoriasis activity FABP5 concentration in patients with severe form of the disease (PASI > 20) was higher compared to the mild group (PASI $<10)(p<0.001)($ Fig. 3$)$.

Serum FABP5 correlated positively with PASI score $(r=0.42, p<0.001)$ (Fig. 4) in all psoriatic patients $(n=$ 74) (Fig. 4). The similar correlation we noticed in the patients group with $B M I<30(r=0.41, p=0.003)$. There was no correlation between PASI score and FABP5 in obese psoriatic patients. We did not find the relationship between FABP5 and disease duration or age of the patients. 
We found positive correlation between FABP5 and basic inflammation indices: C-reactive protein, white blood cell count and the platelet count (Table 2). We have observed also negative correlations with some FA and positive with n-6/n-3 PUVA ratio (Table 3).

\section{Table 2}

Correlation of serum FABP5 with clinical, biochemical and metabolic indices. (BMI- body mass index, PASI - psoriasis area and severity index, CRP - c-reactive protein, WBC - white blood cells, PLT - platelet count, FBG - fasting blood glucose, TG triglycerides, AST - aspartate transaminase, ALT - alanine transaminase )

\begin{tabular}{|c|c|c|}
\hline Correlation of FABP5 with & R Spearman & $p$-value \\
\hline Age (years) & -0.16 & 0.187 \\
\hline Body weight $(\mathrm{kg})$ & -0.24 & 0.037 * \\
\hline $\mathrm{BMI}\left(\mathrm{kg} / \mathrm{m}^{2}\right)$ & -0.20 & 0.090 \\
\hline Disease duration (months) & 0.02 & 0.845 \\
\hline PASI (before NB-UVB) & 0.42 & $<0.001 * \star \star$ \\
\hline CRP [mg/dl] & 0.29 & 0.014 * \\
\hline $\mathrm{WBC}\left[\times 10^{3} / \mathrm{ml}\right]$ & 0.50 & $<0.001^{\star \star \star}$ \\
\hline $\mathrm{PLT}\left[\times 10^{3} / \mathrm{ml}\right]$ & 0.26 & 0.033 * \\
\hline Cholesterol [mg/dl] & 0.01 & 0.966 \\
\hline $\mathrm{TG}[\mathrm{mg} / \mathrm{dl}]$ & 0.06 & 0.650 \\
\hline $\mathrm{FBG}[\mathrm{mg} / \mathrm{dl}]$ & -0.29 & 0.015 * \\
\hline AST [IU/I] & -0.23 & 0.252 \\
\hline ALT [IU/I] & -0.21 & 0.068 \\
\hline Bilirubine [mg/dl] & 0.18 & 0.511 \\
\hline Kreatynine [mg/dl] & -0.27 & 0.114 \\
\hline Vitamin D (before NB-UVB) [ng/ml] & -0.24 & 0.040 * \\
\hline
\end{tabular}


Table 3

Serum FABP5 correlation with the serum free fatty acids.

(FA- fatty acid, PUFA - polyunsaturated fatty acid, SFA saturated fatty acid, UFA - unsaturated fatty acid)

\begin{tabular}{|lll|}
\hline FATTY ACID & R Spearman & p - value \\
\hline Myristic (14:0) & -0.09 & 0.448 \\
\hline Palmitic (16:0) & -0.08 & 0.491 \\
\hline Palmitoleic (16:1n-7) & -0.03 & 0.771 \\
\hline Stearic (18:0) & -0.14 & 0.239 \\
\hline Oleic (18:1n9c) & 0.02 & 0.836 \\
\hline Linoleic (18:2n-6) & 0.02 & 0.871 \\
\hline Arachidic (20:0) & -0.14 & 0.230 \\
\hline a - Linolenic(18:3n-3) & -0.06 & 0.626 \\
\hline Behenic (22:0) & -0.06 & 0.603 \\
\hline Arachidonic (20:4n-6) & -0.36 & 0.002 ** \\
\hline Lignoceric (24:0) & -0.13 & 0.256 \\
\hline Eicozapentaenoic (20:5n-3) & -0.28 & 0.014 * \\
\hline Nervonic (24:1n-9) & -0.03 & 0.826 \\
\hline Docozaheksaenoic (22:6n-3) & -0.27 & $0.021 *$ \\
\hline Total FA & -0.09 & 0.423 \\
\hline n-3 PUFA & -0.28 & $0.017 *$ \\
\hline n-6 PUFA & -0.06 & 0.0602 \\
\hline n-6/n-3 ratio & 0.28 & $0.017 *$ \\
\hline SFA/UFA & -0.08 & 0.522 \\
\hline
\end{tabular}

After the treatment with NB-UVB the median total PASI score decreased from the basal PASI 6.4 to 2.0 ( $p$ $<0.001)$. FABP5 serum concentration decreased significantly from median 6.89 to $6.5(p=0.007)$ (Table 4). 
Table 4

PASI and FABP5 serum concentration before and after treatment with NB-UVB. Data are shown as median and quartiles $\left(\mathrm{Q}_{1}, \mathrm{Q}_{3}\right)$. (PASI - psoriasis area and severity index)

\begin{tabular}{|llll|}
\hline & Before NB-UVB treatment & After NB-UVB treatment & p-value \\
\hline PASI & $6.4(4.4 ; 8.0)$ & $2.0(1.4 ; 2.7)$ & $\mathrm{p}<0.001$ \\
\hline FABP5 ng/ml & $6.89(5.69 ; 9.05)$ & $6.51(3.8 ; 8.15)$ & $\mathrm{p}=0.007$ \\
\hline
\end{tabular}

\section{Discussion}

We examined serum concentration of FABP5 in psoriatic patients with respect to clinical and laboratory data. We demonstrated a significantly higher levels of FABP5 in both groups of psoriatic patients (with and without obesity) compared to the healthy control subjects. We have obtained different results to Miyake et al. who found similar average serum FABP5 level in psoriatic patients and healthy individuals [17]. However authors discovered higher FABP5 level in skin-stripping lesions and uninvolved skin of patients than the skin of healthy individuals. There were some differences between our study group and patients of Miyake. We studied 74 patients with less severe disease (PASI mean 11.3) versus 31 patients (PASI mean 17.3). Our patients did not use any topical or systemic treatment prior to the study. Patients of Miyake used topical steroids and/or vitamin D ointments. Topical treatment, specially steroids and vitamin $D$, may have some immunomodulatory effect and influence the results. There are several studies confirming high expression of FABP5 in psoriatic skin lesions and in uninvolved skin of psoriatic patients compared to the healthy skin $[14,17,18]$. Authors suggest that FABP5 plays an important role in keratinocyte differentiation [14]. Higher serum concentration of FABP5 in our study may reflect its epidermal level. The underlying mechanism of the association of FABP5 and psoriasis is not clear yet, but one of the possible explanation is role of the adaptive immune system, particularly of Th1 and Th17 lymphocytes, which has been regarded as prominent in the immunopathogenesis of psoriasis [19]. Interestingly, studies have shown that FABP5 can increase Th17-cell differentiation [20] and aberrant FABP5 activity may over activate immune cells leading to inflammatory autoimmune diseases [21].

The positive correlation of serum FABP5 with basic inflammation indices: C-reactive protein, white blood cell count and the platelet count in our study, seems to confirm the notion that FABP5 follows the inflammatory process in psoriasis and may play an important role in the pathogenesis of psoriasis and, what is more, may be used as a biomarker of severity of the disease.

High level of FABP5 can have also some metabolic implications. In the other studies serum FABP5 levels correlated positively with parameters of adiposity, adverse lipid profiles, serum insulin, adipocyte fatty acid binding proteins (A-FABP, FABP4), C-reactive protein levels and were higher in subjects with the metabolic syndrome (MS). The association of FABP5 with the MS and carotid atherosclerosis in humans was independent of FABP4. According to Yeung et al FABP5 is a new circulating biomarker associated with increased cardio-metabolic risk [22]. Similar results have been obtained by Bagheri et al. whose 
findings suggested that FABP4 and FABP5 may represent mediators of and biomarkers for metabolic and cardiovascular disease in type 2 diabetes mellitus [16]. Furthermore, Ibarretxe et al. revealed that FABP5 was associated with increased subclinical atherosclerosis and higher FABP5 plasma levels was associated with the presence of type 2 diabetes, obesity, metabolic syndrome, or atherogenic dyslipidemia [23]. The meta-analysis of 35 studies and 1,450,188 participants revealed that psoriatic patients have higher prevalence to MS compared to general population. [2]. In psoriasis MS is diagnosed in about $31.4 \%$ of patients [24]. Subsequently, numerous studies have demonstrated that psoriasis, particularly severe disease, is associated with increased risk of cardiovascular diseases [8,25]. Our results may indicate that elevated serum FABP5 represents another link between psoriasis MS and cardiovascular comorbidities.

On the other hand, in the last decade, modern epidemiological studies have provided strong evidence that obesity predisposes patients to the development of psoriasis and amplifies psoriatic inflammation [26, 27] The analysis of metabolic factors indicated that adiposity is a central factor in this association [28]. Zhang $Y$ et al. reported that FABP5 expression from the high-fat diet-induced obese mice was 2-fold higher in keratinocytes and 6-fold higher in macrophages as compared to the controls. This results indicate the high-fat diet upregulates FABP5 in the skin tissues and promotes inflammation of the skin [29]. Sometimes it is difficult to point out what has came first in the metabolic dysregulation or inflammation. On both sides, elevated serum FABP5 observed in our study may contribute to the further immunologic and metabolic dysregulation.

Additionally, we have found a negative correlation of serum FABP5 with serum concentration of arachidonic (AA), eicosapentaenoic (EPA), docosahexaenoic (DHA) fatty acids and positive correlation with $n-6 / n-3$ ratio of polyunsaturated fatty acids (PUFA). According to the literature, FABP5 has a broad range of ligands, including saturated and unsaturated fatty acids like: linoleic acid, EPA, DHA, AA and their derivatives [30]. In general, EPA and DHA are able to inhibit different mechanism of inflammation while n-6 PUFA promote production of inflammatory cytokines and T cell reactivity through production of prostaglandins and leukotrienes from AA [31]. Positive correlation of FABP5 with $n-6 / n-3$ ratio highlights the pro-inflammatory state promoting metabolic disturbances in psoriatic patients.

Psoriasis is often accompanied by NAFLD. We have not observed correlation of FABP5 with liver function tests in the present study. However, such connection was reported by Ishimura in general population [32]. Our study group was free of liver diseases and the levels of transaminases were within the normal range so, based on our results, we cannot conclude about connection of FABP5 and NAFLD in psoriasis.

To the best of our knowledge, this is the first study evaluating influence of NB-UVB on serum concentration of FABP5 in patients with chronic plaque psoriasis. We have observed significant decrease of serum FABP5 after the effective NB-UVB treatment. There was only one study comparing an effect of different methods of treatment on FABP5 levels in skin-stripping [17]. The authors have reported decreased levels of skin FABP5 among 7 (out of 10) studied patients. Two of them were treated with adalimumab, 3 with infliximab and 2 with NB-UVB. It is difficult to compare this results with our study. 
Firstly, because FABP5 was evaluated in different tissue and secondly, it was very small group of patients. Nevertheless, we can again speculate that the serum concentration of FABP5 may reflect its level in the skin. What was interesting, according to Miyake et al., skin- stripping FABP5 decreased prior to the clinical improvement, so it could help to predict the result of the treatment. Further prospective studies are needed to investigate if the serum concentration decrease also precedes the improvement of skin lesions. Reduction of FABP5 after treatment may indicate improvement of metabolic condition of psoriatic patients. Similar results (reduction of plasma FABP5) were obtained in morbid obese patients after gastric binding-induced weight loss [33]. Authors also suggested that FABP5 may be associated with metabolic improvement. In this context, it should further be noted that weight loss in obese psoriatic patients may improve skin lesions [34].

The main limitation of our study is lack of metabolic control after the NB-UVB. We have studied only the FABP5 and vitamin D concentration after the treatment, so we are not able to compare the FABP5 with inflammation and metabolic indices. However, significant reduction of PASI is relatively strong evidence clinical improvement. Subsequent limitation of the study is small group of patients. To have more comprehensive view, it would be the best to extend the number of patients and make a comparison in subgroups with different comorbidities.

\section{Conclusion}

In our study elevated serum level of FABP5 in psoriatic patients correlates with the disease severity and accompanies indicators of systemic inflammation. Our findings may suggest that serum concentration of FABP5 could be used as a novel clinical biomarker of inflammation and disease severity in psoriasis. Moreover, aberrant FABP5 indicate metabolic abnormalities which may result in the development of metabolic syndrome and cardiovascular diseases. Furthermore, NB-UVB treatment reduces FABP5 serum concentration which may indicate metabolic state improvement. Taken together, our results have additional value in the growing body of evidence indicating a common metabolic profile between psoriasis and cardiometabolic diseases. Therefore, understanding the possible relationship between them is an important issue that may lead to the development of more effective therapies.

\section{Abbreviations}

AA - Arachidonic Acid

AST - Aspartate transaminase,

ALT - Alanine transaminase

BMI - Body mass index

CER - Ceramides 
CRP - C-reactive protein

DHA - Docozaheksaenoic acid

EFABP - Epidermal Fatty acid binding protein

ELISA - Enzyme-Linked Immunosorbent Assay

EPA - Eicozapentaenoic acid

FABP - Fatty acid binding protein

FA - Fatty acids

FBG - Fasting blood glucose

FFA - Free fatty acids

HDL - High density lipoprotein

LDL - Low density lipoprotein

MUFA - Monounsaturated fatty acids

MS - Metabolic syndrome

n-3 PUFA - n-3 polyunsaturated fatty acids

NAFLD - Non-alcoholic fatty liver disease

NB-UVB - Narrow band ultraviolet B radiation

PASI - Psoriasis area and severity index

PUFA - Polyunsaturated fatty acids

S1P - sphingosine-1-phosphate

SFA - Saturated fatty acids

TG - Triglycerides

UFA - Unsaturated fatty acids

WBC - White blood cells

PLT - Platelet count 


\section{Declarations}

\section{Acknowledgements}

Not applicable.

\section{Funding}

This study was supported by a study grant from the Medical University of Bialystok (SUB/1/DN/19/002/1149)

\section{Availability of data and materials}

Not applicable.

\section{Authors' contributions}

DK and HM performed the study, analyzed the results and write the manuscript. EHS and AM helped in performing experiments and assisted in statistical analysis and manuscript writing. AC and IF supervised the study and reviewed the paper. All authors read and approved the final manuscript.

\section{Ethics approval and consent to participate}

All procedures performed in the study involving human participants were in accordance with the ethical standards of the Bioethical Committee of Medical University of Białystok and with the 1964 Helsinki declaration and its later amendments or comparable ethical standards(permission nr R-I-002/53/2018). Informed consent was obtained from all individual participants included in the study.

\section{Consent for publication}

Not applicable.

\section{Competing interests}

The authors have no conflicts of interest to declare 


\section{References}

1. Gisondi P, Tesari G, Conti A, Piaserico S, Schianchi S, Peserico A, Giannetti A, Girolomoni G.

Prevalence of metabolic syndrome in patients with psoriasis: a hospital-based case-control study. $\mathrm{Br}$ J Dermatol. 2007; 157:68-73.

2. Singh S, Young P, Armstrong AW. An update on psoriasis and metabolic syndrome: A meta-analysis of observational studies. PLoS One. 2017;12, doi: 10.1371/journal.pone.0181039.

3. Strand V, Gonçalves J, Hickling TP, Jones HE, Marshall L, Isaacs JD. Immunogenicity of Biosimilars for Rheumatic Diseases, Plaque Psoriasis, and Inflammatory Bowel Disease: A review from clinical trials and regulatory documents. BioDrugs. 2020;34:27-37.

4. Miller IM, Ellervik C, Yazdanyar S, Jemec GB. Meta - analysis of psoriasis, cardiovascular disease, and associated risk factors. J Am Acad Dermatol. 2013; 69:1014-24.

5. Magdaleno-Tapial J, Valenzuela-Oñate C, Ortiz-Salvador JM, Martínez-Doménech Á, García-LegazMartínez M, Alonso-Carpio M, Tamarit-García JJ, Diago-Madrid M, Sánchez-Carazo JL, Pérez-Ferriols A. Prevalence of non-alcocholic fatty liver and liver fibrosis in patients with moderate-severe psoriasis: a cross-sectional cohort study. Australas J Dermatol. 2020;61:105-109.

6. Chiricozzi A, Raimondo A, Lembo S, Fausti F, Dini V, Costanzo A, Monfrecola G, Balato N, Ayala F, Romanelli $\mathrm{M}$, et al. Crosstalk between skin inflammation and adipose tissue-derived products: pathogenic evidence linking psoriasis to increased adiposity. Expert Rev Clin Immunol. 2016;12:1299-1308.

7. Kamiya K, Kishimoto M, Sugai J, Komine M, Ohtsuki M. Risk factors for the development of psoriasis. Int J Mol Sci. 2019;20:4347. doi: 10.3390/ijms20184347.

8. Mehta NN, Azfar RS, Shin DB, Neimann AL, Troxel AB, Gelfand JM. Patients with severe psoriasis are at increased risk of cardiovascular mortality: Cohort study using the General Practice Research Database. Eur Heart J. 2010; 31:1000-1006.

9. Springate DA, Parisi R, Kontopantelis E, Reeves D, Griffiths CE, Ashcroft DM. Incidence, prevalence and mortality of patients with psoriasis: a U.K. population-based cohort study. Br J Dermatol. 2017;176:650-658.

10. Furuhashi M, Hotamisligil GS. Fatty acid-binding proteins: role in metabolic diseases and potential as drug targets. Nat Rev Drug Discov. 2008;7:489-503.

11. Sikora M, Stec A, Chrabąszcz M, Waskiel-Burnat A, Zaremba M, Olszewska M, Rudnicka L. Intestinal Fatty Acid Binding Protein, a biomarker of intestinal barrier is associated with severity of psoriasis. $J$ Clin Med. 2019;8:1021. doi: 10.3390/jcm8071021

12. Baran A, Świderska M, Bacharewicz-Szczerbicka J, Myśliwiec H, Flisiak I. Serum fatty acid-binding protein 4 is increased in patients with psoriasis. Lipids. 2017;52:51-60.

13. Khnykin D, Miner JH, Jahnsen F. Roleof fatty acid transporters in epidermis: implications for health and disease. Dermatoendocrinol 2011;3:53-61. 
14. Smathers RL, Petersen DR. The human fatty acid-binding protein family: evolutionary divergences and functions. Hum Genomics 2011;5:170-191.

15. Dallaglio K, Marconi A, Truzzi F, Lotti R, Palazzo E, Petrachi T, Saltari A, Coppini M, Pincelli C. E-FABP induces differentiation in normal human keratinocytes and modulates the differentiation process in psoriatic keratinocytes in vitro. Exp Dermatol. 2013;22:255-61.

16. Bagheri R, Qasim AN, Mehta NN, Terembula K, Kapoor S, Braunstein S, Schutta M, Iqbal N, Lehrke M, Reilly MP. Relation of plasma fatty acid binding proteins 4 and 5 with the metabolic syndrome, inflammation and coronary calcium in patients with type-2 diabetes mellitus. Am J Cardiol. 2010;106:1118-23.

17. Miyake T, Ogawa E, Mikoshiba A, Kobayashi A, Hosoe H, Kashiwabara, S, Uhara H, Owada Y, Okuyama R. Epidermal-type FABP is a predictive marker of clinical response to systemic treatment and ultraviolet therapy in psoriatic skin lesions. J Dermatol Sci.2012; 68:199-202.

18. Masouye I, Saurat JH, Siegenthaler G. Epidermal fatty-acid-binding protein in psoriasis, basal and squamous cell carcinomas: an immunohistological study. Dermatology. 1996; 192:208-213.

19. Furiati, SC, Catarino JS, Silva MV, Silva RF, Estevam RB, Teodoro RB, Pereira S, Ataide M, Rodrigues VJr, Rodrigues DBR. Th1, Th17, and Tregresponses are differently modulated by TNF- a inhibitors and methotrexate in psoriasis patients. Sci Rep. 2019;9: 7526.

20. Li B, Reynolds JM, Stout RD, Bernlohr DA, Suttles J. Regulation of Th17 differentiation by epidermal fatty acid-binding protein. J Immunol. 2009;182:7625-33.

21. Zhang Y, Li B. E-FABP: regulator of immune function. Oncoscience. 2014;1:398-399.

22. Yeung DC,Wang $Y, X u$ A, Cheung SC, Wat NM, Fong DY, Fong CH, Chau MT, Sham PC, Lam KS. Epidermal fatty-acid-binding protein: a new circulating biomarker associated with cardio-metabolic risk factors and carotid atherosclerosis. Eur Heart J. 2008;29:2156-63.

23. Ibarretxe D, Girona J, Amigo N, Plana N, Ferre R, Guaita S, Mallol R, Heras M, Masana L. Impact of epidermal fatty acid binding protein on 2D-NMR-assessed atherogenic dyslipidemia and related disorders. J Clin Lipidol. 2016;10:330-338.

24. Rodriguez-Zuniga MJM, Garcia-Perdomo HA. Systematic review and meta-analysis of the association between psoriasis and metabolic syndrome. J Am Acad Dermatol. 2017;77:657-66.

25. Puig L. Cardiometabolic comorbidities in psoriasis and psoriatic arthritis. Int J Mol Sci. 2018;19, 58.

26. Setty AR, Curhan G, Choi HK. Obesity, waist circumference, weight change, and the risk of psoriasis in women: nurses' health study II. Arch Intern Med. 2007;167:1670-75.

27. Snekvik I, Smith CH, Nilsen TIL, Langan SM, Modalsli EH, Romundstad PR, Saunes M. Obesity, waist circumference, weight change, and risk of incident psoriasis: prospective data from the HUNT study. J Invest Dermatol. 2017;137:2484-90.

28. Snekvik I, Nilsen TIL, Romundstad PR, Saunes M. Metabolic syndrome and risk of incident psoriasis: prospective data from the HUNT Study, Norway. Br J Dermatol. 2019;180:94-99. 
29. Zhang Y, Li Q, Rao E, Sun Y, Grossmann ME, Morris RJ, Cleary MP, Li B. Epidermal fatty acid binding protein promotes skin inflammation induced by high-fat diet. Immunity. 2015;42:953-64.

30. Sanson B, Wang T, Sun J, Wang L, Kaczocha M, Ojima I, Deutsch D, Li H. Crystallographic study of FABP5 as an intracellular endocannabinoid transporter. Acta Crystallogr D Biol Crystallogr. 2014;70:290-98.

31. Qin S, Wen J, Bai XC, Chen TY, Zheng RC, Zhou GB, Ma J, Feng JY, Zhong BL, Li YM. Endogenous n3 polyunsaturated fatty acids protect against imiquimod-induced psoriasis-like inflammation via the IL-17/IL-23 axis. Mol Med Rep. 2014;9:2097-2104.

32. Ishimura S, Furuhashi $M$, Watanabe $Y$, Hoshina K, Fuseya $T$, Mita T,Okazaki $Y$, Koyama M, Tanaka $\mathrm{M}$, Akasaka $\mathrm{H}$. et al. Circulating levels of fatty acid-binding protein family and metabolic phenotype in the general population. PLoS One. 2013;8:e81318. doi:10.1371/journal.pone.0081318.

33. Haider DG, Schindler K, Bohdjalian A, Prager G, Luger A, Wolzt M, Ludvik B. Plasma adipocyte and epidermal fatty acid binding protein is reduced after weight loss in obesity. Diabetes Obes Metab. 2007;9:761-63.

34. Alotaibi HA. Effect of weight loss on psoriasis: a review of clinical trials. Cureus. 2018;10:e3491. doi 10.7759/cureus.3491.

35. Schmitt J, Wozel G. The Psoriasis area and severity index is the adequate criterion to define severity in chronic plaque-type psoriasis. Dermatology. 2005;210:194-99.

36. Glaser C, Demmelmair H, Koletzko B. High-throughput analysis of total plasma fatty acid composition with direct in situ transesterification. PLoS One. 2010;5(8):e12045. doi:10.1371/journal.pone.0012045.

\section{Figures}




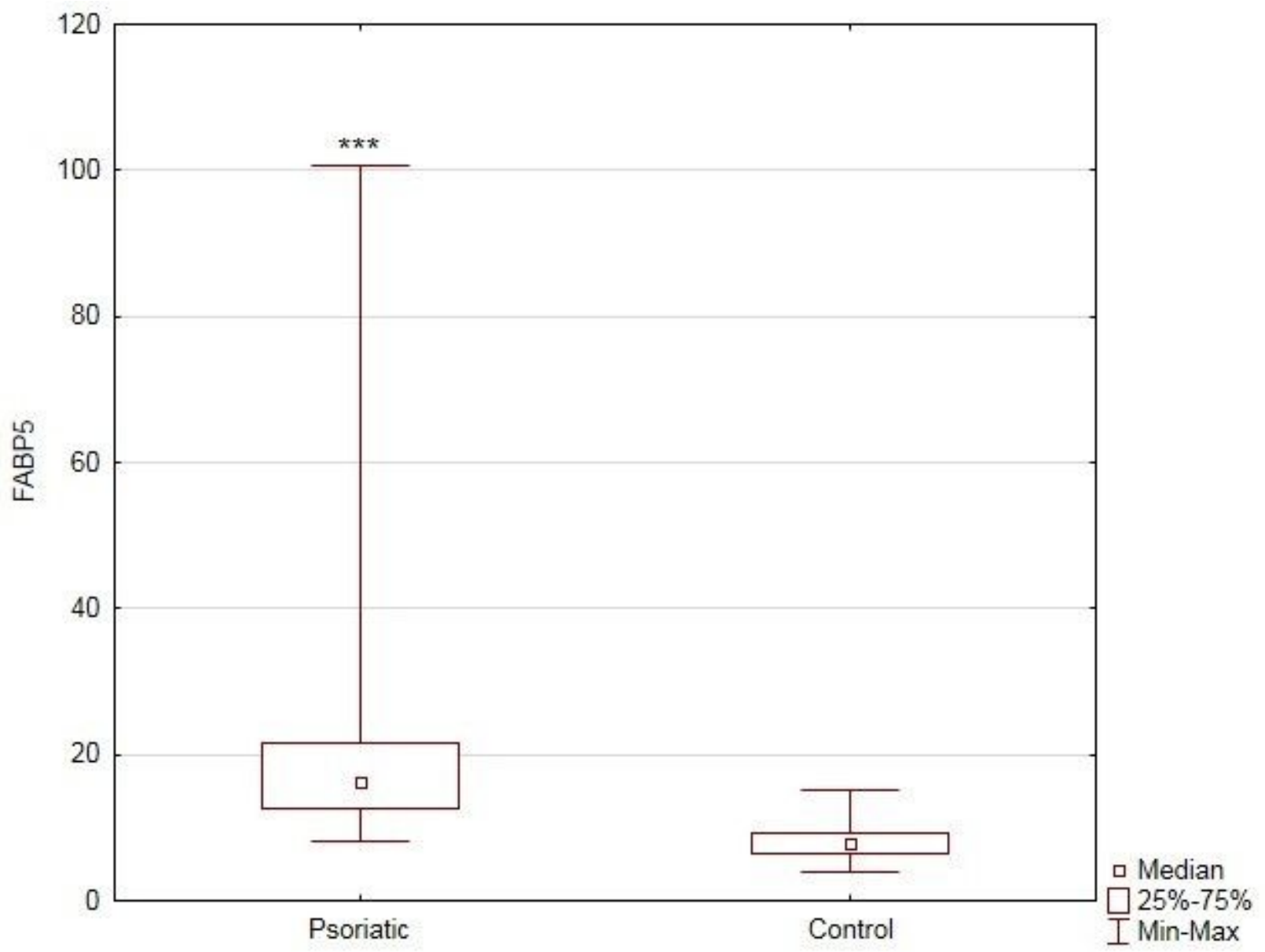

\section{Figure 1}

Comparison of serum FABP5 concentrations between patients and controls. Data shown as median (Q1, Q3). Significant difference between the groups $p<0.001 * \star \star$ 


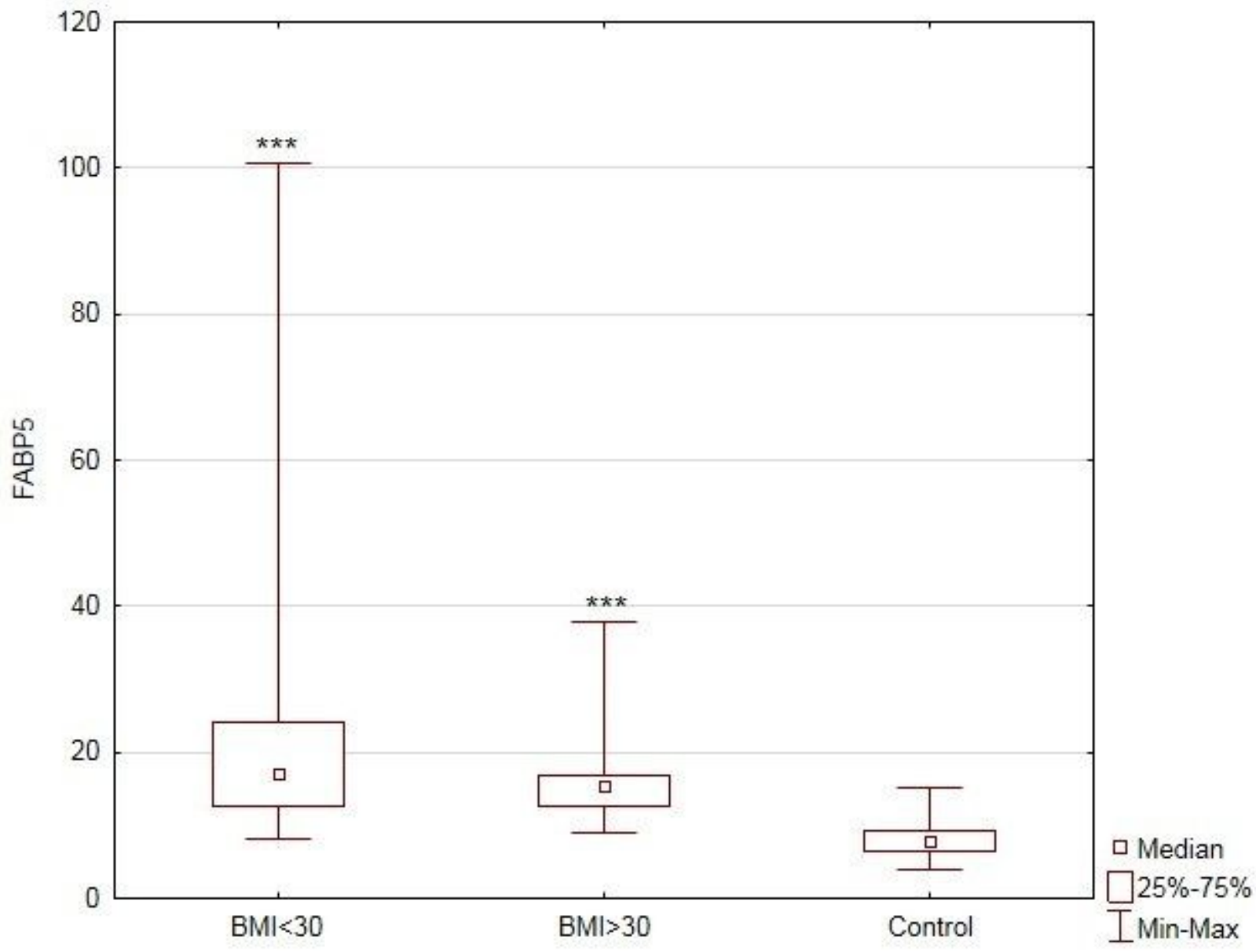

Figure 2

Comparison of serum FABP5 concentrations between non-obese, obese patients and controls. Data shown as median and quartiles (Q1, Q3). Significant difference between the groups was observed $p$ $<0.001^{\star \star \star}$ (BMI- body mass index) 


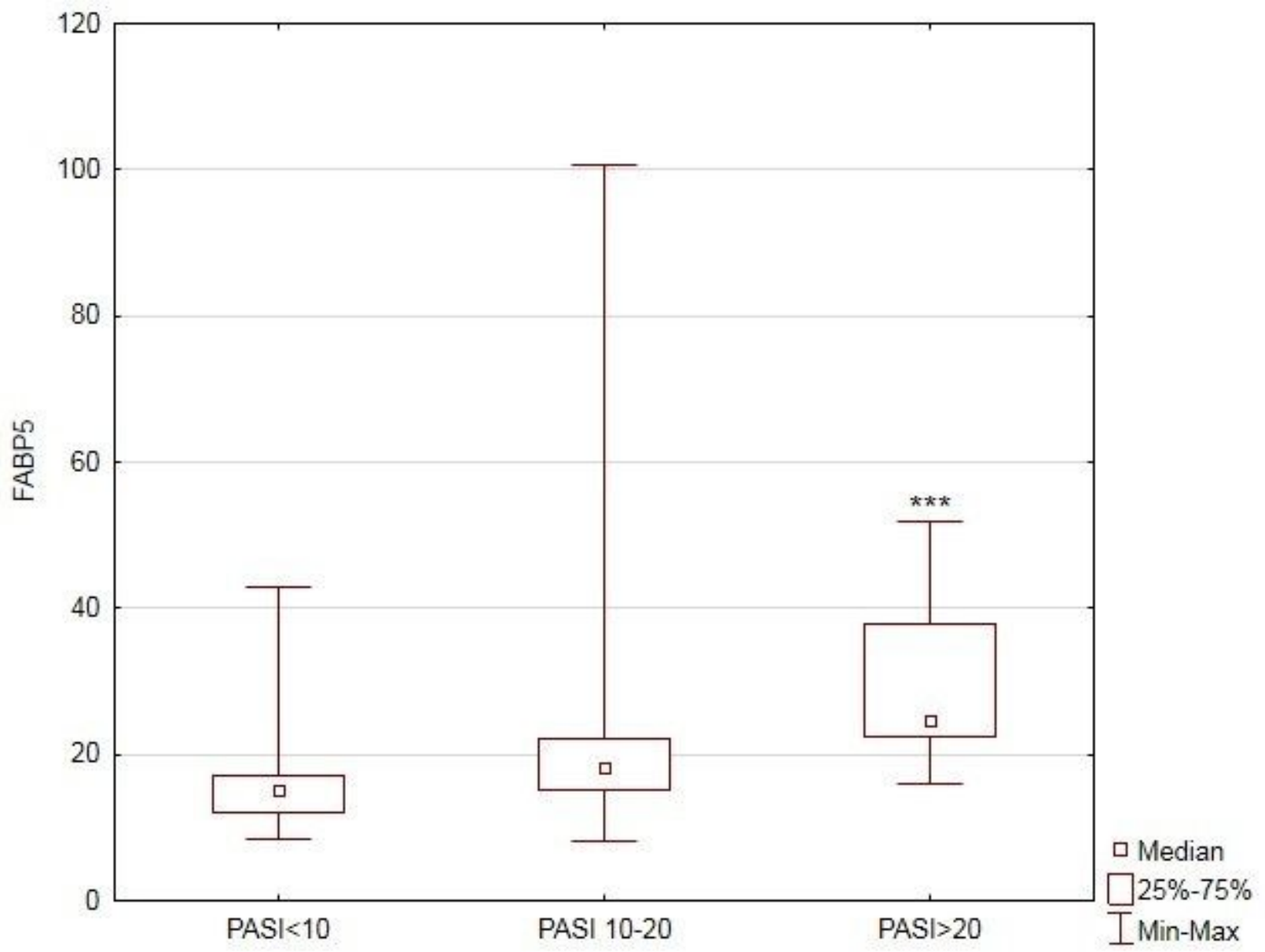

\section{Figure 3}

Comparison of serum FABP5 concentrations between patients according to the severity of the disease.

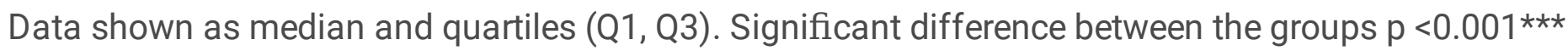
(PASI - psoriasis area and severity index) 


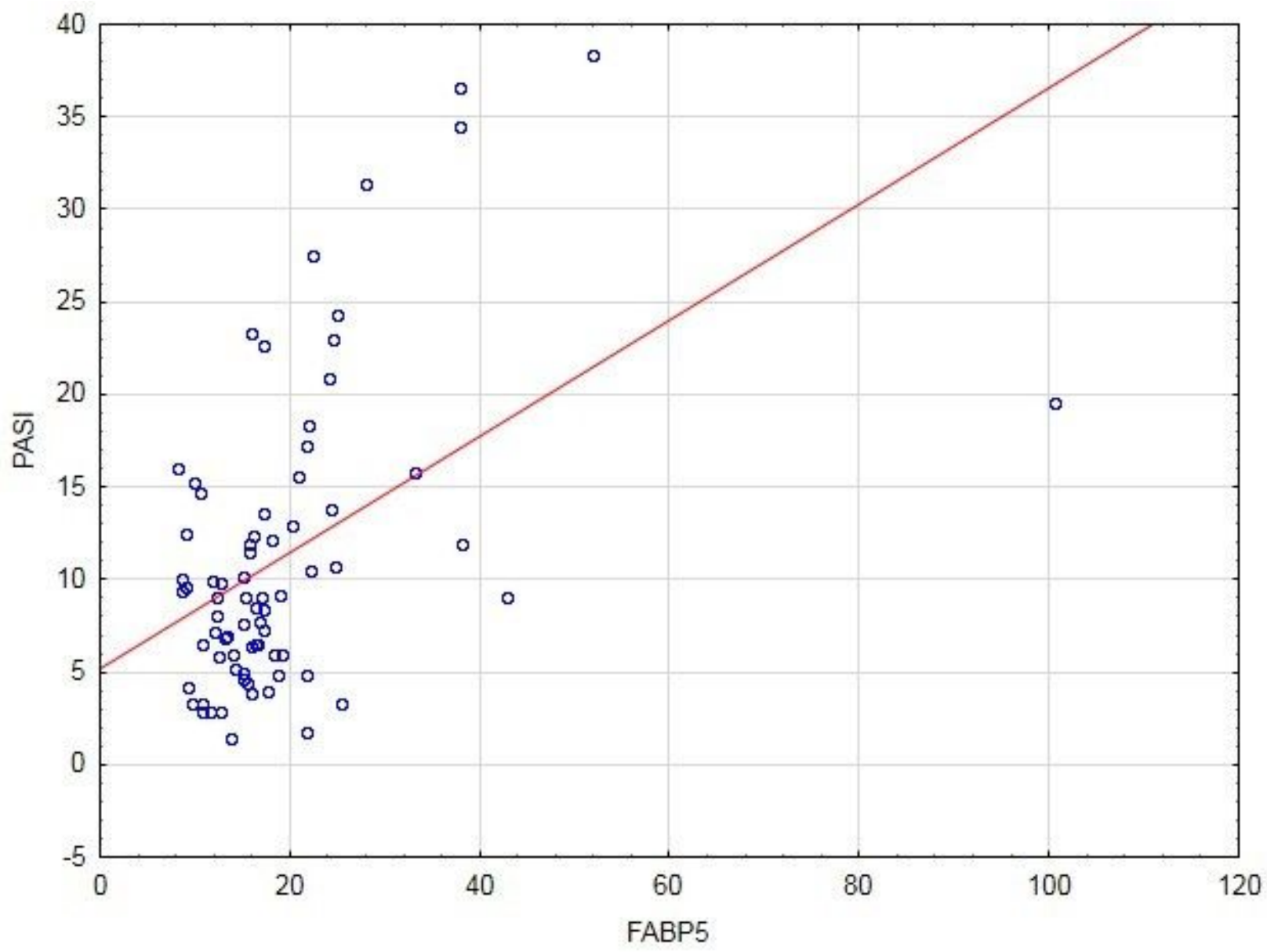

Figure 4

Correlation between concentrations of serum FABP5 and PASI $(n=74)(r=0.42, p<0.001)$. (PASI - psoriasis area and severity index) 